\title{
Effect of the insulation by the mud on the convection in building in the Sahara of Algeria - case of Bechar City
}

\author{
Elhadj Benachour ${ }^{1, a}$, Belkacem Draoui ${ }^{1}$, Baachir Imine ${ }^{2}$, Mohammed Hasnat ${ }^{1}$, Lakhdar Rahmani ${ }^{1}$ \\ ${ }^{1}$ Laboratory of Energy in Arid Regions, University of Tahri Mohamed - Bechar, P.O. P 417. 08000 , Road Kenedza, Bechar, Algeria \\ ${ }^{2}$ Department of Mechanical Engineering, University of Sciences and Technology of Oran-Mohamed Boudiaf, P.O.1505 El-Mnaouar, Oran, \\ Algeria
}

\begin{abstract}
The thermal behavior of the buildings is a current problem which arouses the interest of many researchers. Indeed, the control of the loads of air conditioning or heating requires a thorough knowledge. Since the thermal quality of the buildings in the Maghreb is there generally very insufficient in particular in the Sahara of Algeria, the insulation proved that it is a very important parameter to minimize the thermal diffusion process inside on all when the insulator is a local material as the Mud which is in our region with a significant amount and almost free quantity. This work presents a study of numerical simulation aiming at the role and the influence of the insulation by the mud Reduced like a local material to the town of Bechar located at the south west of Algeria, or one is interested in a comparative study for pursued these goals. In this context, an analogy was used for the functions which are discretized by the finite difference method and integrated in the Fluent code which is based on the finite volume method. The validation of this procedure was confirmed while comparing some results. The results are presented in the form of distributions of the isotherms, the streamlines, local and average Nusselt of which the goal to study the influence on comfort.
\end{abstract}

\section{Introduction}

The thermal behavior of buildings is a current problem which arouses the interest of numerous and many researchers. Indeed, energy consumptions and greenhouse gas emissions are very high to the world. It is thus necessary to reduce the energy needs while improving the energy efficiency, in particular in the sector of the building. This one offers possibilities of considerable reduction of the energy consumption, in particular by improving the thermal insulation [1]. To reduce them, various strategies are organized, among which several aim at the improvement of the energy efficiency of buildings [2-5]. We indeed notice that numerous housing is not isolated yet. About $65 \%$ of the walls of housing arrange no insulation. A significant portion and An important part of these not isolated external walls are massive solid brick walls or the thermal perceived in buildings was aimed by some research [6-9]. Other works suggested studying the effect of the insulation on the energy consumptions and the energy performances in buildings. The insulation of the external walls is complex and several processes exist: insulation by filling of the slide, insulation by outside and insulation by the interior. In restoration, it very often arrives that the choice is restricted for technical reasons, economic and/or patrimonial reasons. Although it can generate many risks on the level of the hygrothermic and mechanical behavior of the walls, Then, since the thermal isolation is one of the investments of most profitable energy saving, in particular in the new building, Several numerical studies and experimental were realized[10-16]. The insulation by the interior then becomes often the only possible solution in particular with the buildings in the Sahara of Algéria. The hygrothermic parameters of the existing wall and reported materials must be well-known to design powerful and durable walls in time.

Our study consists in studying the thermal transfer through walls. Two types of walls are studied:

- A not isolated wall,

- A wall isolated inside by the mud.

This work presents a study of numerical simulation aiming at the role and at the influence of the insulation by the mud as a local material at the city of Bechar situated in the south west of Algeria, or we are interested in a comparative study for aimed these goals. In this context, an analogy was used for the used functions which are discretized by the finite difference method and integrated in the Fluent code which is based on the finite volume method. The validation of this procedure was confirmed by comparing some obtained results. The results are presented in the form of distributions of isotherms,

Stream lines and the local Nusselt number and average Nusselt number of whom (which) the purpose to study the influence on the comfort.

\footnotetext{
${ }^{\mathrm{a}}$ Corresponding author: benachour_elhadj@yahoo.fr
} 


\section{Geometric configuration}

By giving itself two configurations, the one being described the wall without insulation, and the other one with insulation by the mud. The studied configuration is represented on the figure 1 . We chose the most widespread construction in the area. The studied room is a structure of a multi-house zone, but in is interested in only one, of dimension $16 \mathrm{~m}^{3}(4 \times 4 \times 4)$.To simplify the calculation we are interested in a phenomenon of two dimensions. The outer walls are simple concrete walls of $20 \mathrm{~cm}$, with the mortar coating outside surface of negligible thickness compared to the thickness of the outside wall. The roof is insulated [supposed or presumedly adiabatic]. And on the bottom floor earth (ground) is a concrete slab with a wooden frame [supposed adiabatic]. Temperatures imposed on interior and exterior walls are captured experimentally in one day of a summer of August the Bechar city to 15h00.Then to model this phenomenon. This is a square cavity of length $\mathrm{L}$ and a height $\mathrm{h}$. The left and right vertical walls of the cavity are heated to a constant temperature equal to $\mathrm{Tc} 48^{\circ} \mathrm{C}(\mathrm{Tc}=1$ for the dimensionless case) $\mathrm{Tf}$ equal to $25^{\circ} \mathrm{C}(\mathrm{Tf}=0.5$ for the dimensionless case $)$, and the other walls are maintained adiabatic. One will exploit the existence and the absence of the interior insulation to facilitate the comparative study. The thickness of concrete wall $\mathrm{e}_{1}=\mathrm{L} / 20$, and the thickness of the insulation interior by the Mud is $e_{2}=\mathrm{L} / 20$. The factor of the form is $\mathrm{A}=1$.
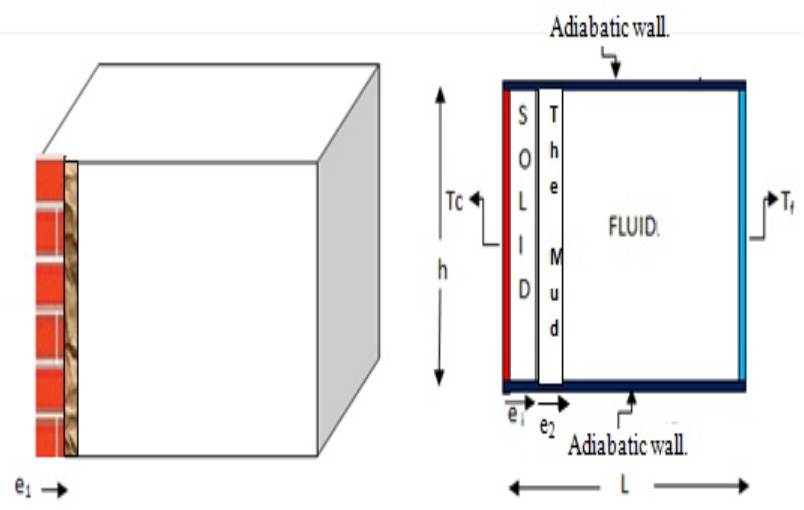

Figure 1. Schematic of the studied configuration

To simplify the problem, assume that:

- The fluid is Newtonian and incompressible.

- The heat dissipation by viscous friction is neglected.

- The Boussinesq approximation is considered

\section{Objects}

We can express our aim for this study in the following points:

- Study the Modelling of the coupling of convection - conduction.

- Study of the effect of the distribution of the heat inside buildings on the convection.
- Comparative study between the construction of buildings with and without insulation.

- Study the effect of the Rayleigh number on the convection in building.

- Test the reliability of the insulation with the Mud as local material.

\section{Mathematical model}

The fluid is assumed incompressible and obeys the Boussinesq approximation. In these cases, continuity in two dimensions and the equations governing the flow and energy is given by:

Continuity.

$$
\frac{\partial U}{\partial X}+\frac{\partial V}{\partial Y}=0
$$

X-momentum.

$$
\frac{\partial U}{\partial t}+U \frac{\partial U}{\partial X}+V \frac{\partial U}{\partial Y}=-\frac{1}{\rho} \frac{\partial P}{\partial X}+v \nabla^{2} U
$$

\section{Y-momentum.}

$$
\frac{\partial V}{\partial t}+U \frac{\partial V}{\partial X}+V \frac{\partial V}{\partial Y}=-\frac{1}{\rho} \frac{\partial P}{\partial X}+v \nabla^{2} V+g \beta \frac{\partial T}{\partial X}
$$

\section{Energy.}

$$
\frac{\partial T}{\partial t}+U \frac{\partial T}{\partial X}+V \frac{\partial T}{\partial Y}=\frac{\lambda}{\rho \mathcal{C}_{p}} \nabla^{2} T+\frac{1}{\rho_{\mathcal{C}_{p}}} \varphi
$$

The derived equation of motion (2) over $\mathrm{Y}$ and the equation of motion (3) by contributing to $\mathrm{x}$, then, after subtracting the two equations obtained, we obtain the equations dimensionless variables in writing Helmotz in terms of vorticity and stream function formulation are as follows:

$$
\begin{gathered}
\frac{\partial \omega}{\partial t}+U \frac{\partial \omega}{\partial X}+V \frac{\partial \omega}{\partial Y}=\operatorname{Pr} \nabla^{2} \omega+\operatorname{Ra} \operatorname{Pr} \frac{\partial T}{\partial X} \\
\frac{\partial T}{\partial t}+U \frac{\partial T}{\partial X}+V \frac{\partial T}{\partial Y}=\frac{\partial^{2} T}{\partial X^{2}}+\frac{\partial^{2} T}{\partial Y^{2}}+\frac{\varphi}{\rho C p} \frac{L^{2}}{a \Delta T} \\
\frac{\partial^{2} \psi}{\partial X^{2}}+\frac{\partial^{2} \psi}{\partial Y^{2}}=-\omega
\end{gathered}
$$

The stream function and vorticity are related to the velocity components by the following expressions:

$$
U=\frac{\partial \psi}{\partial Y}, V=-\frac{\partial \psi}{\partial X} \text { and } \omega=\frac{\partial V}{\partial X}-\frac{\partial U}{\partial Y}
$$


The dimensionless parameters in the equations above are defined as follows:

$$
\left\{\begin{array}{l}
X=\frac{x}{H}, \quad Y=\frac{y}{H}, \quad U=\frac{u}{u_{i}} \\
V=\frac{v}{u_{i}}, P=\frac{P}{\rho u_{i}{ }^{2}}, T=\frac{T-T_{i}}{T_{c}-T_{i}}, t^{*}=\frac{t}{L^{2} / a}
\end{array}\right.
$$

For solid, we are interested only in the following heat equation:

$$
\frac{\partial T}{\partial t}=\frac{1}{a}\left(\frac{\partial^{2} T}{\partial x^{2}}+\frac{\partial^{2} T}{\partial y^{2}}\right)
$$

\section{Procedure of Simulation}

The numerical calculation was conducted using the computer code "fluent" 6.2.13. The numerical procedure used in this work is that of finite volume.

It involves the integration of differential equations of mathematical model on finite control volumes for the corresponding algebraic equations.

The SIMPLE algorithm [17] was chosen for the coupling speed pressure in the Navier-Stokes equations on a staggered grid. The convective terms in all equations are evaluated using the schema upwind first order.

The discretization of the time term is made in a totally implicit scheme. The convergence of the solution is considered reached when the maximum relative change of all variables $(\mathrm{u}, \mathrm{v}, \mathrm{w}, \mathrm{p}, \mathrm{t})$ between two successive time is not less than $10^{4}$.

With an aim of following well any variation of the fields thermal and hydrodynamic, we used a uniform grid of 14241 nodes and 14480 Elements in nonstationary mode.

\section{Validation of the Code of Calculation}

\subsection{Validation of the model}

The computer code was validated on a natural convection problem of stale air in a square cavity with vertical walls differentially heated and adiabatic horizontal walls. Our results were compared with those obtained by De Vahl Davis (1983) [18] .The latter dealt with the same problem by adopting the finite difference method with the vorticity-stream function formulation (see Table 1).
Table1. Comparisons of the results of validation

\begin{tabular}{|c|c|c|c|}
\hline & $\mathbf{R a}=\mathbf{1 0}^{\mathbf{3}}$ & $\mathbf{R a}=\mathbf{1 0}^{\mathbf{4}}$ & $\mathbf{R a}=\mathbf{1 0}^{\mathbf{5}}$ \\
\hline $\begin{array}{c}\text { Nu } \\
\text { (average } \\
\text { number) } \\
\text { (hot wall) }\end{array}$ & $\begin{array}{c}\text { present } \\
\text { study: }\end{array}$ & $\begin{array}{c}\text { present } \\
\text { study : }\end{array}$ & $\begin{array}{c}\text { Present } \\
\text { study : }\end{array}$ \\
\hline $\begin{array}{c}\text { Nu } \\
\text { (average } \\
\text { number) } \\
\text { (hot wall) }\end{array}$ & $\begin{array}{c}\text { De Vahl } \\
\text { Davis } \\
{[\mathbf{1 8}]:}\end{array}$ & $\begin{array}{c}\text { De Vahl } \\
\text { Davis [18]: }\end{array}$ & $\begin{array}{c}\text { De Vahl } \\
\text { Davis [18] : }\end{array}$ \\
1.12 & 2.243 & 4.52 \\
\hline
\end{tabular}

\section{Results and Discussion}

The structure of the flow, the temperature field and heat transfer through the hot wall are discussed in this section.

In this study, to target the most important goal, we will show and studied the effect of the insulation by the Mud on dynamic and thermal behavior of the fluid in the cavity.

\subsection{Isotherms}

The isotherms are shown in Figures [2-9]. The heat distribution in the cavity is in accordance with the fluid circulation revealed by isotherms and iso currents. Indeed we find a heating fluid from the interface, if it causes the change of the heat distribution in the cavity (see figures) for different numbers of Rayleigh For a fixed value of the number of Prandtl equal 0.71.

Gradually, as the Rayleigh number has increased, the isotherms become increasingly wavy and heat transfer increases, so the flow intensifies and natural convection is expanding and predominates (natural convection is predominant).

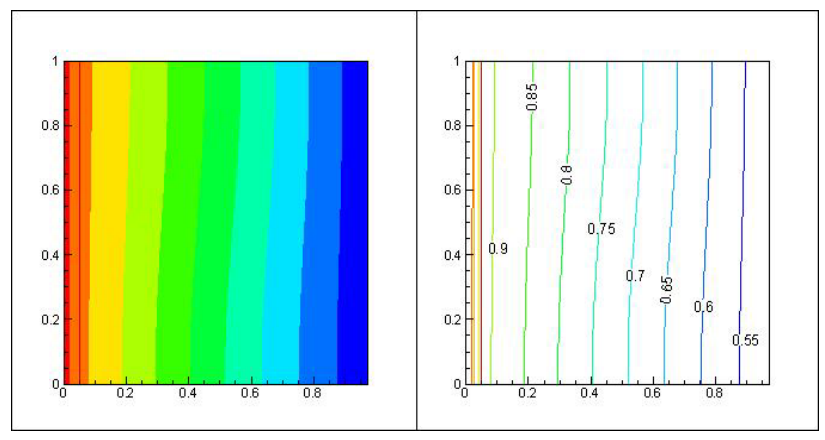

Figure 2. The Isotherms For uninsulated wall, Rayleigh Number Equal $10^{3}, \mathrm{Pr}=0.71$ 


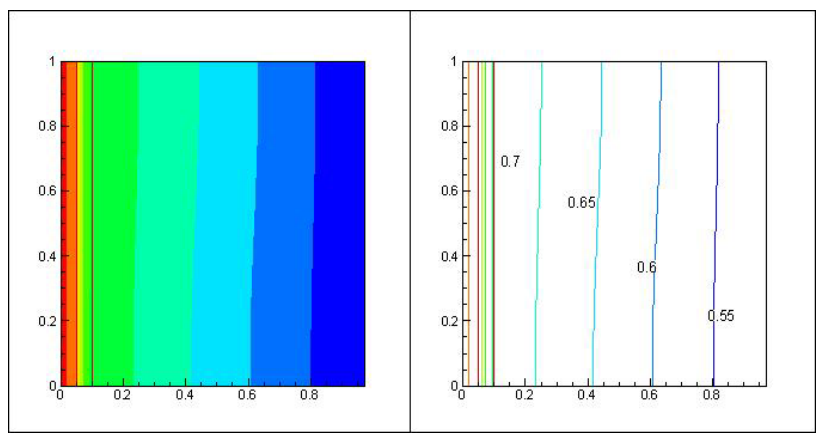

Figure 3. The Isotherms For Insulated Wall, Rayleigh Number Equal $10^{3}, \operatorname{Pr}=0.71$

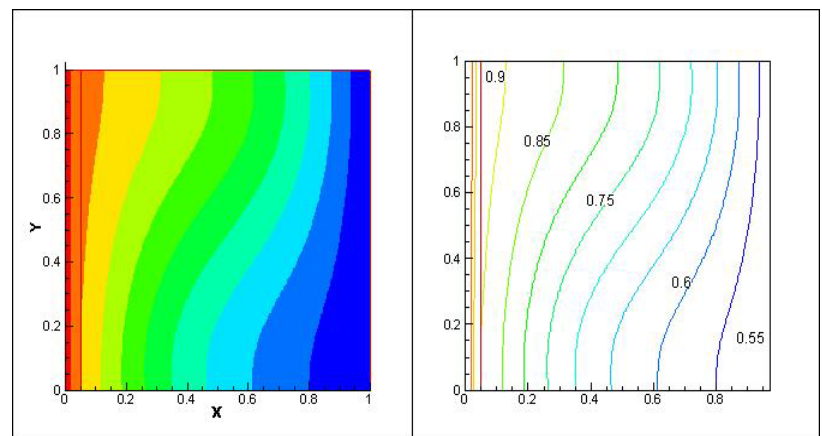

Figure 4. The Isotherms For uninsulated wall, Rayleigh Number Equal $10^{4}, \operatorname{Pr}=0.71$

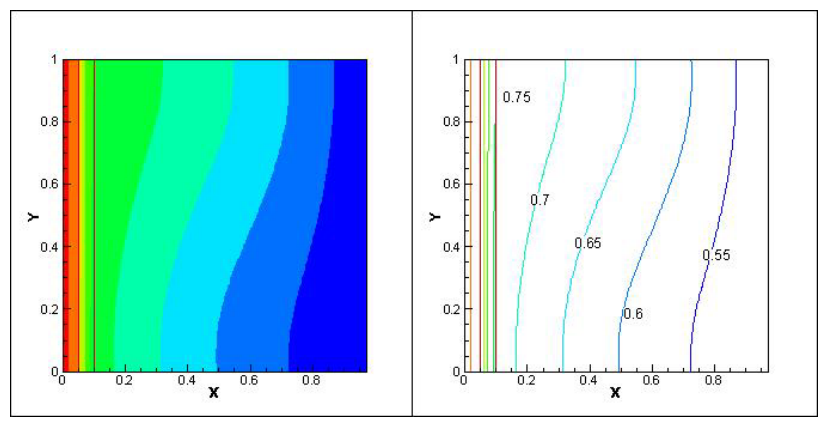

Figure 5. The Isotherms For Insulated Wall, Rayleigh Number Equal $10^{4}, \operatorname{Pr}=0.71$

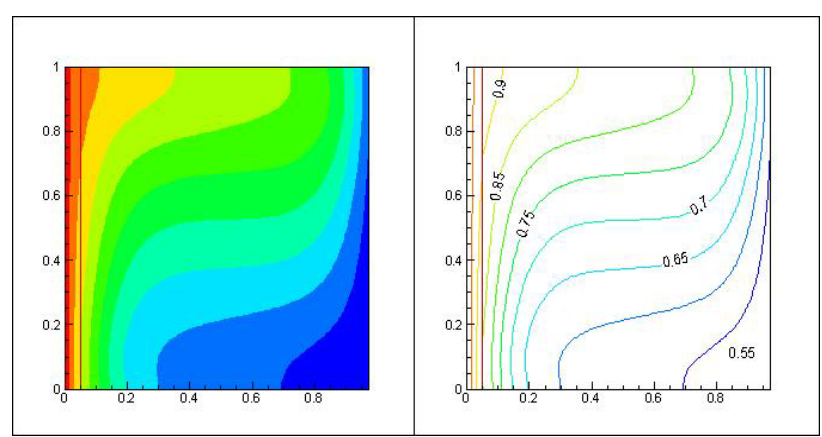

Figure 6.The Isotherms For uninsulated wall, Rayleigh Number Equal $10^{5}, \operatorname{Pr}=0.71$

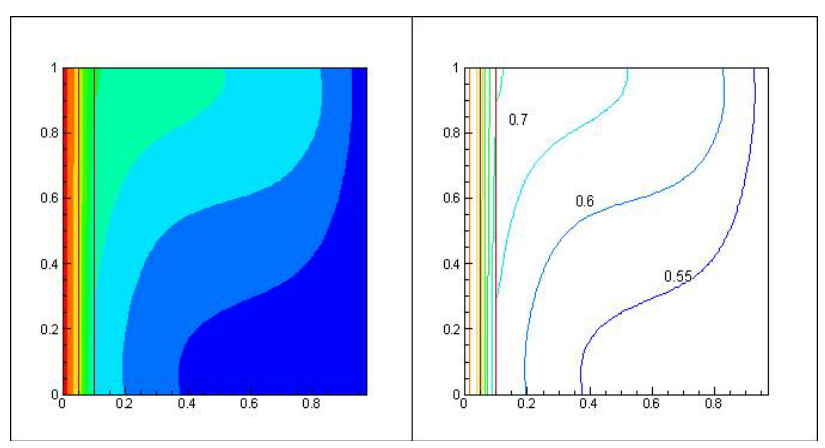

Figure 7. The Isotherms For Insulated Wall, Rayleigh Number Equal $10^{5}, \operatorname{Pr}=0.71$

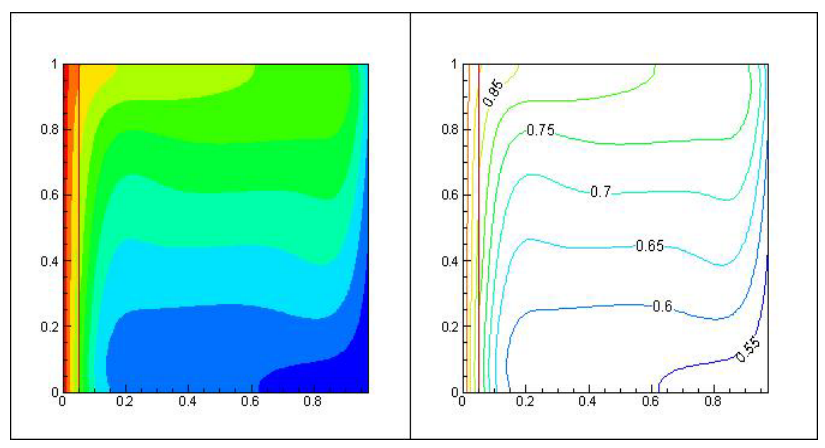

Figure 8.The Isotherms For uninsulated wall, Rayleigh Number Equal $10^{6}, \operatorname{Pr}=0.71$

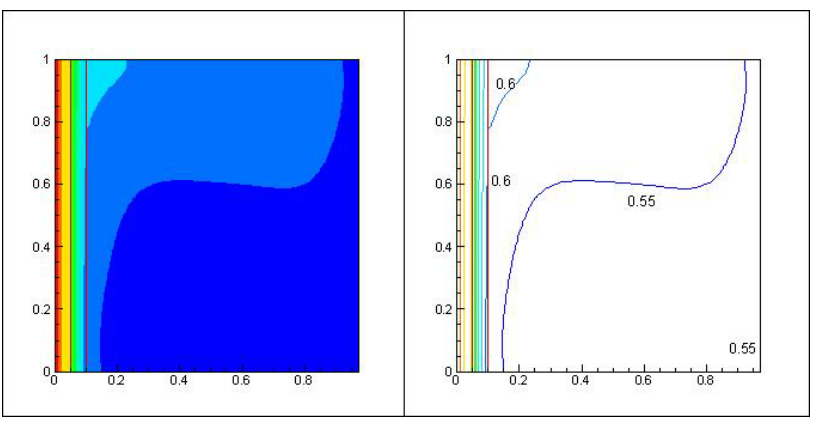

Figure 9. The Isotherms For Insulated Wall, Rayleigh Number Equal $10^{6}, \operatorname{Pr}=0.71$.

\subsection{Streamlines}

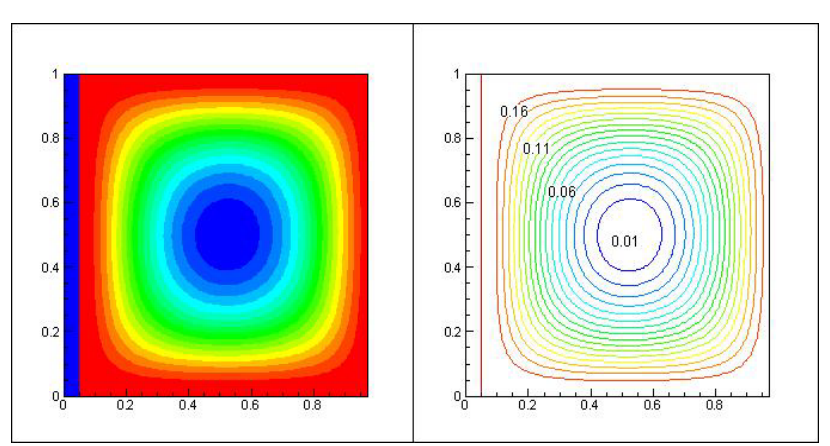

Figure 10. Streamlines obtained For uninsulated wall, Rayleigh Number Equal $10^{3}, \mathrm{Pr}=0.71$ 


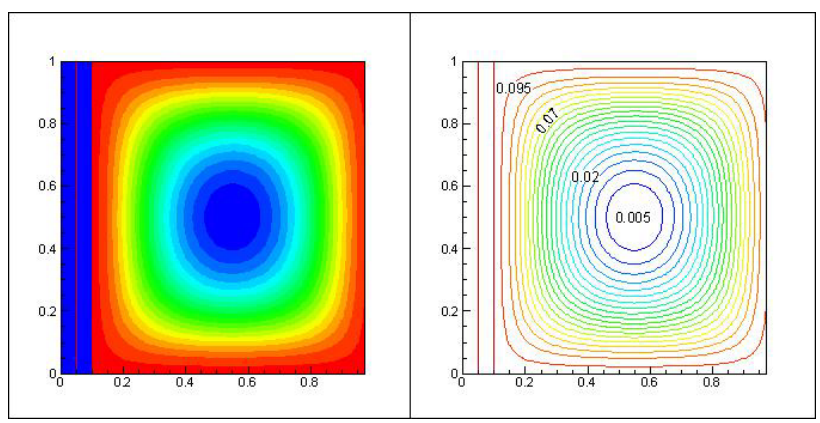

Figure 11. Streamlines obtained For Insulated wall, Rayleigh Number Equal $10^{3}, \operatorname{Pr}=0.71$

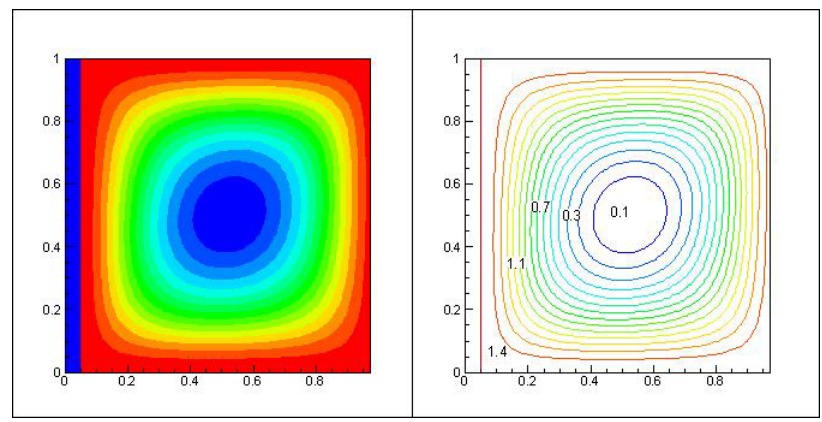

Figure 12. Streamlines obtained For uninsulated wall, Rayleigh Number Equal $10^{4}, \mathrm{Pr}=0.71$

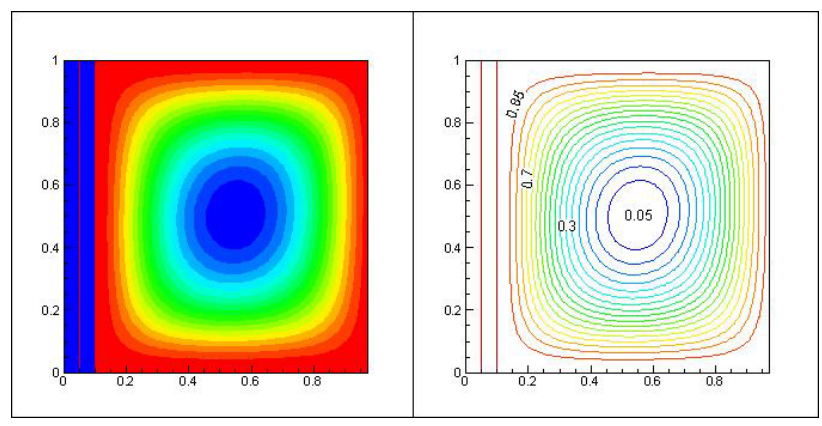

Figure 13. Streamlines obtained for Insulated wall, Rayleigh Number Equal $10^{4}, \operatorname{Pr}=0.71$.

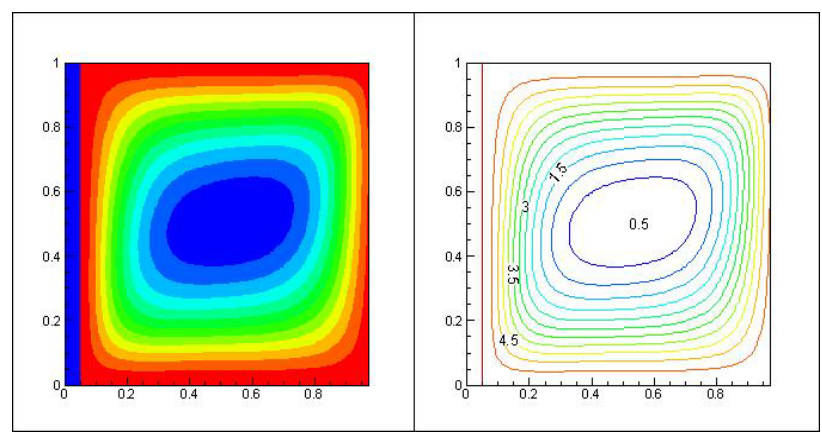

Figure 14. Streamlines obtained for uninsulated wall, Rayleigh Number Equal $10^{5}, \operatorname{Pr}=0.71$

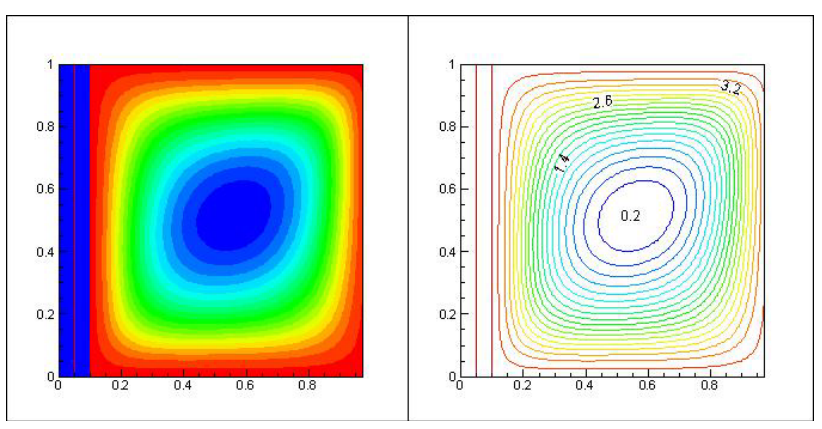

Figure 15. Streamlines obtained For Insulated Wall, Rayleigh Number Equal $10^{5}, \operatorname{Pr}=0.71$.

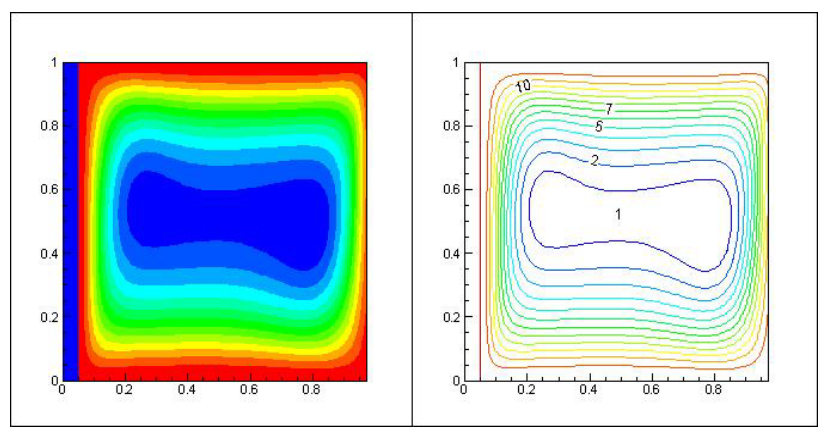

Figure 16. Streamlines obtained for uninsulated wall, Rayleigh Number Equal $10^{6}, \mathrm{Pr}=0.71$

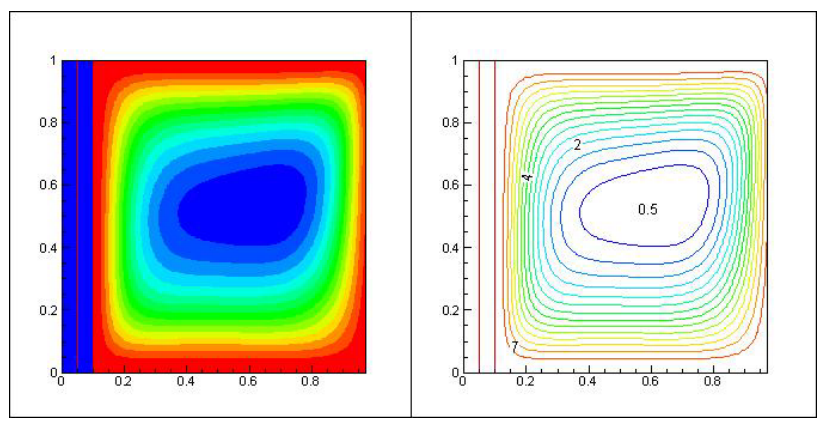

Figure 17. Streamlines obtained for Insulated Wall, Rayleigh Number Equal $10^{6}, \operatorname{Pr}=0.71$

Figures [10-17] shows the current lines corresponding to Rayleigh numbers: $10^{3}, 10^{4}, 10^{5}$ and $10^{6}$ with a value of Prandt $=0.71$ For uninsulated and Insulated Walls . When $\mathrm{Ra}=10^{3}$, the flow is almost symmetric, we see that there are cells that are closed on itself, the fluid motion was a motion block, which justifies the existence of recirculation zones closer the center of the cavities, the flow lines are substantially parallel to the vertical walls. So also for the representation of flow lines corresponding to the Rayleigh number equal to $10^{4}, 10^{5}$, we find that the current lines are tight at the vertical walls and in the middle, this is due to strong temperature gradient at the vertical walls and thus the flow is parietal which characterizes the large convective heat transfer to the vertical walls. We also observed the formation of two cells in the recirculation cavity for $10^{6}$ same. It is also noted in the latter case, the expansion of two areas of recirculation of a cell in the clockwise direction and the other in the opposite direction, with the increase of Rayleigh. 


\subsection{Temperature profiles}

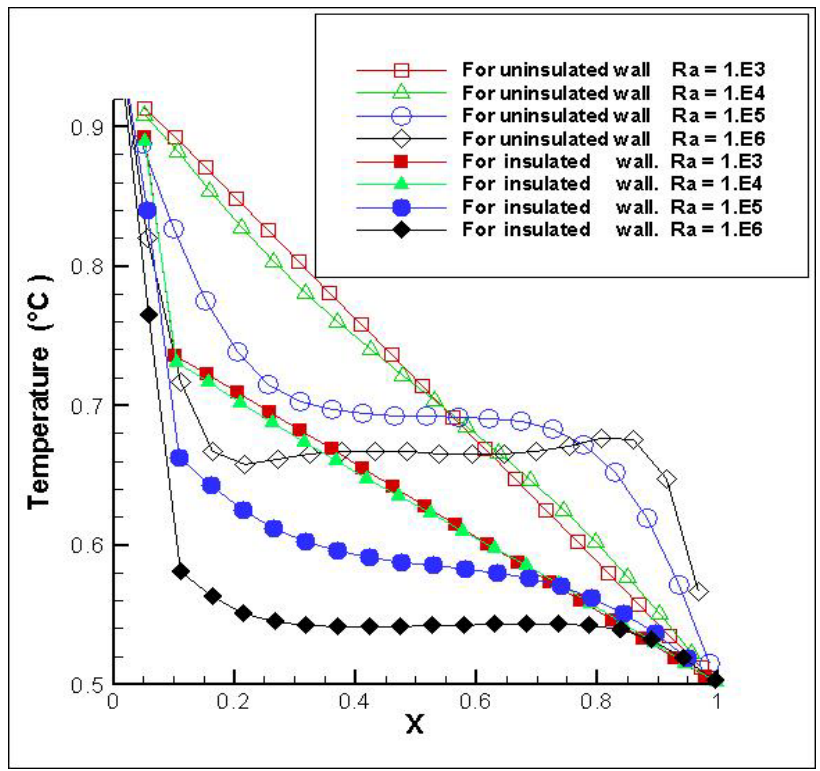

Figure 18. Dimensionless horizontal temperature profiles for different Rayleigh numbers for uninsulated and insulated walls, $\operatorname{Pr}=0.71, \mathrm{Y}=0.5$

Observation of the temperature profiles for different values of $y=0.5$ (Figure 18) to Rayleigh leads us to confirm that the increase of temperature takes the form of the parabola is to say, this increase is condensed in the middle irrespective of the number Rayleigh, but it is sensitive, we can say there is a direct proportionality.

\subsection{Nusselt numbers}

We report in Figure 20 the influence of the Rayleigh number on average Nusselt number. We found a significant influence of the Rayleigh number. The increase in average Nusselt number is accompanied with the increase of Rayleigh, but after the Rayleigh number equal to $10^{5}$, the heat transfer is almost the same, and then represents the better heat transfer in the cavity.

The local Nusselt number is presented in Figure 19, it is clear that it becomes important for every increase of Rayleigh because of the change in the exchange ratio between the wall and the air, a difference of around $16 \%$ on average, between insulated and uninsulated walls to $\mathrm{Ra}=10^{5}$, which can be doubled to $\mathrm{Ra}=10^{6}$.

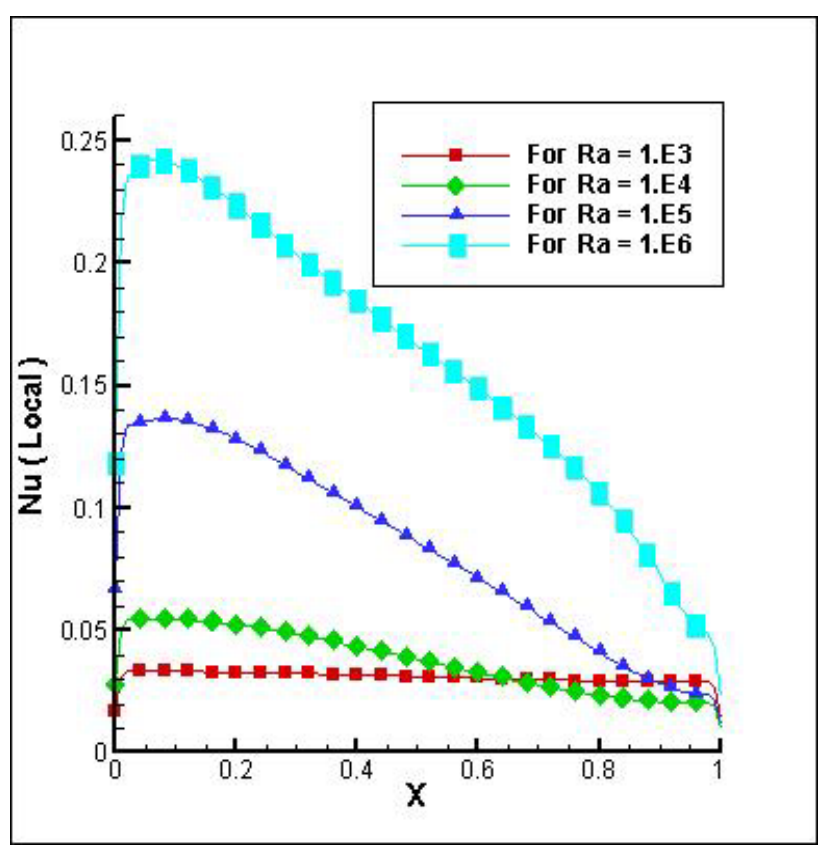

Figure 19. Profiles of Local Nusselt number, for different values of $\mathrm{Ra}=10^{3}, 10^{4}, 10^{5}$ and $10^{6}$, for insulated walls, $\operatorname{Pr}=0.71$.

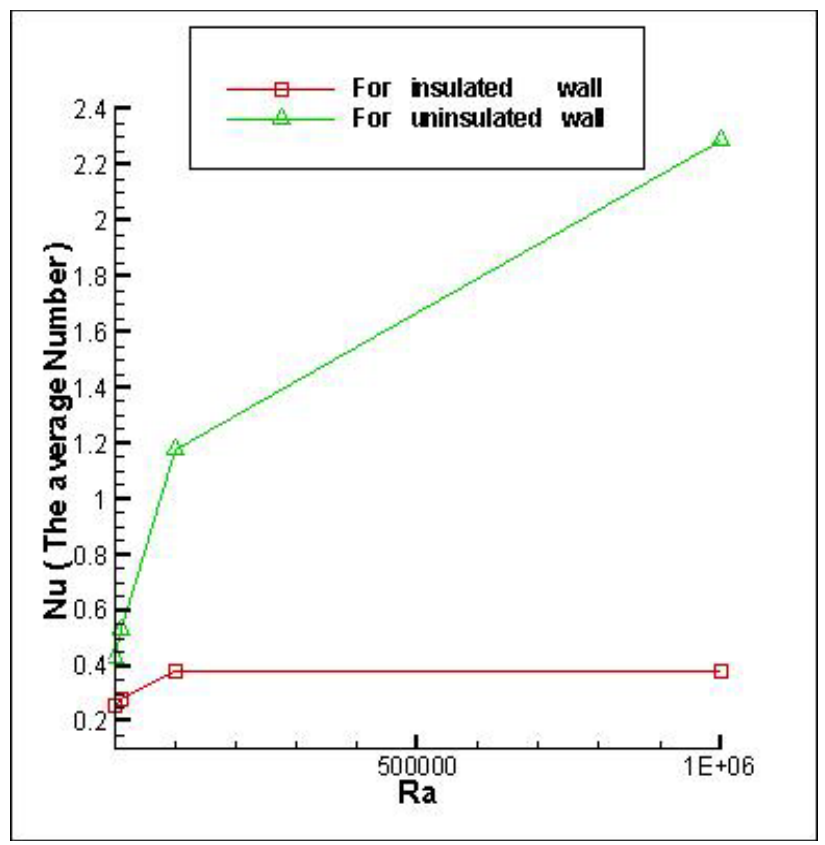

Figure 20. Profiles of average Nusselt number for different values of $\mathrm{Ra}=10^{3}, 10^{4}, 10^{5}$ and $10^{6}$, for uninsulated and insulated walls, $\operatorname{Pr}=0.71$.

\section{Conclusion}

The idea of this work is based on actual events; this is just the underfloor heating in buildings arides. The objective of our work was to study the behavior of the air in enclosed with two-dimensional numerical study of natural convection or (where) laminar flow is considered on is interested by conduction or convection coupling. Solving equations governing natural convection written Helmontz's variables $\psi$ and $\omega$ which are discretized by 
the finite difference method. We validated the work in the literature for the hydrodynamic and thermal studies in the cavities where he showed good consistency. For our simulation, we presented the streamlines, isotherms and the influence of key parameters such as positioning after the interface and the number of Rayleigh convection. We have shown by this simulation, the following:

1. Convection affects the structure of the isotherms.

2. The temperature of the fluid increases dramatically with increase in Rayleigh number.

3. The Interior thermal isolation reduces the losses of heat and minimizes the energy needs (request of heating) and thus reduced in fact, at the same time: the invoice, consumption and pollution.

4. The Mud is insulating effective which to guarantee the comfort and the air quality inside the building

5. The interior thermal insulation helps to preserve a constant temperature in the integrality of your housing winter like summer.

6. The Inside thermal insulation has a promising future provided that all actors, around the sector of construction are justified and motivated and conscious of the ecological and financial issues.

\section{References}

1. R. Guechchati, M.A. Moussaoui, Ahm. Mezrhab and Abd. Mezrhab, Simulation of the effect of the thermal insulation of buildings psychoeducational center Cas du centre psychopédagogique Case of SAFAA in Oujda, Renewable Energy Review, Vol. $13 \mathrm{~N}^{\circ} 2,223-232,(2010)$.

2. R. Belarbi, M. Spérandio et F. Allard, Evaluation of the Building industries Provided with Systems of Passive Cooling. Application to the Case of Adiabatique' Evaporation, General Review of Thermics, Vol. 36, N7, pp. 547 - 561, (1997).

3. C. lnard, P. Depecker et J. Roux, A Model Simplified for the Prediction of the Field of Temperature in the Building industries, General Review of Thermics, Vol. 36, N², pp. 113 123,(1997).

4. G.A. Florides, S.A. Tassou, S.A. Kalogirou, L.C. Wrobel, 'Measures Used to Lower Building Energy Consumption and Their Cost Effectiveness', Applied Energy, Vol. 73, N³, pp. 299 328,( 2002).

5. F.F. Al-Ajmi and V.I. Hanby, 'Simulation of Energy Consumption for Kuwaiti Domestic Buildings', Energy and Buildings, Vol. 40, N6, pp. 1101 1109, (2008).

6. M.S. Mohsen and B.A. Akash, 'Some Prospect of Energy Saving in Building', Energy

Conversion Management, Vol. 42, N¹1, pp. 1307 1315, (2001)
7. M.A. Aktacir, O. Büyükalaca and T. Yılmaz, 'A Case Study for Influence of Building Thermal Insulation on Cooling Load and Air-Conditioning System in the Hot and Humid Regions', Applied Energy, Vol. 87, N², pp. 599 - 607, (2010).

8. L. Peeters, R. de Dear, J. Hensen and W. D'haeseleer, 'Thermal Comfort in Residential Buildings: Comfort Values and Scales for Building Energy Simulation', Applied Energy, Vol. 86, N5, pp. 772 - 780, (2009).

9. E. Benachour and al, Effect of positioning the heating element on natural convection in a square cavity (habitat type), international review of mechanical engineering, vol.4N.5, July (2010).

10. A. Mecke, I. Lee, J.R. Baker jr., M.M. Banaszak Holl, B.G. Orr, Eur. Phys. J. E 14, 7 (2004).

11. U. Eicker, V. Fux, U. Bauer, L. Mei and D. Infield, 'Façades and Summer Performance of Buildings', Energy and Buildings, Vol. 40, N4, pp. 600 - 611, (2008).

12. D. Medjelakh et S. Abdou, 'Impact of Thermal Inertia on Hygrothermic Comfort and the Energy consumption of the bâtiment', Review of Renewable energies, Vol. 11, N³, pp. 329 - 341, (2008).

13. L. Peeters, R. de Dear, J. Hensen and W. D'haeseleer, 'Thermal Comfort in Residential Buildings: Comfort Values and Scales for Building Energy Simulation', Applied Energy, Vol. 86, N5, pp. 772 - 780, (2009).

14. S.A. Klein, W.A. Beckman and J.A. Duffie, 'TRNSYS - A Transient Simulation Program', ASHRAE Transactions, Vol. 82, N¹, pp. 623 - 633, (1976).

15. S.A. Klein, W.A. Beckman, J.W. Mitchel, J.A. Duddie, N.A. Duffie and T.L. Freeman, 'TRNSYS Manual', University of Wisconsin, (2006).

16. N. Fezzioui, B. Draoui, M. Benyamine et S. Larbi, 'Influence of the Dynamic Characteristics of the Envelope of Building on Thermal Comfort in the South Algéria', Review of Renewable energies, Vol. 11, $\mathrm{N}^{\circ} 1$, pp. 25 - 34, (2008).

17. S. V. Patankar, Numerical Heat Transfer and Fluid Flow, McGraw-Hill New York, ( 1980).

18. De Vahl Davis G, Natural convection of air in a square cavity. A bench mark numerical solution. (1983). 